\title{
DO WE NEED ADJUVANTS? MECHANISTIC STUDIES AND IMPLICATIONS FOR FUTURE DEVELOPMENTS
}

\author{
D. STOCK
}

\author{
Formulation Department, AgrEvo UK Ltd, Chesterford Park, \\ Saffron Walden, Essex CB10 1XL, UK
}

\begin{abstract}
Whilst adjuvant materials have been used for many decades, the basis for their application with pesticides has often been empirical. Due to pressures on the crop protection industry, there has been increased motivation for rational scientific evaluation of the mode(s) of action of adjuvants. An increased understanding offers the potential for optimised delivery and dose reduction, with associated cost and environmental benefits. Changes in preferred formulation types may necessitate increased adjuvant usage to maintain activity. The continuing role of adjuvants will be influenced by biotechnology and its impact on conventional crop protection chemistry. However, chemical inputs within integrated crop management regimes are likely to continue for many decades.
\end{abstract}

Keywords: adjuvant, formulation, mechanisms, regulation, penetration, retention

\section{INTRODUCTION}

Additives have been used for many years in combination with foliage-applied pesticides in order to increase the activity or, more accurately, the apparent activity of compounds. Historically adjuvants have been used predominantly with herbicides, and this is reflected in the overwhelming bias of the open literature towards this field. Some adjuvantsper se are not new concepts, so consideration must be given to why the use of such materials may be considered part of an emerging technology.

The term "adjuvant" has numerous meanings and has been the source of unending confusion. Within Great Britain the regulatory authorities recognise an adjuvant to be any material other than water with no biological activity in its own right which enhances the activity of a pesticide when tank-mixed. However, the preceding definition is not universal. For example, in France, an adjuvant may be part of a pesticide formulation. Clearly, such non-standardisation of terminology leads to confusion, particularly when many formulation components, such as emulsifiers, have activation properties in their own right and may equally be described as adjuvants (Stock 1996). Irrespective of such semantics, adjuvant-type materials can be categorised according to both their chemistry and mode of action. It must be stressed, however, that an adjuvant may have more than one mode of action. Categorisation by chemistry therefore provides the most meaningful overview of materials currently available, especially when the proposed mode(s) of action for many materials is often (tenuous) theory rather than scientific fact. A summary of the major types of adjuvant currently used is provided in Table 1.

The major category of tank-mix adjuvant is oils (Uttley 1995). Historically, these have been of mineral origin, but are gradually being superseded by vegetable oils and their derivatives. The second major category of adjuvants are surfactants (surface-active agents). These include a wide range of materials which can be nonionic or ionic in nature. Amongst other chemical categories are various polymers, film forming materials and inorganic salts.

TABLE 1: Main types of adjuvant currently available for tank-mixing. 


\begin{tabular}{|c|c|c|}
\hline Chemistry & Examples & Mode(s) of action \\
\hline $\begin{array}{l}\text { Organic surfactants } \\
\text { (ionic and nonionic) }\end{array}$ & Agral, Ethokem & $\begin{array}{l}\text { Enhanced foliar retention } \\
\text { increased penetration, coverage }\end{array}$ \\
\hline Organosilicone & $\begin{array}{l}\text { Silwet L-77, } \\
\text { Sylgard } 309\end{array}$ & $\begin{array}{l}\text { Enhanced foliar coverage, } \\
\text { stomatal flooding, enhanced } \\
\text { rainfastness }\end{array}$ \\
\hline $\begin{array}{l}\text { Oils (mineral, vegetable, } \\
\text { transesterified vegetable) }\end{array}$ & $\begin{array}{l}\text { Actipron, Codacide, } \\
\text { Actirob B }\end{array}$ & $\begin{array}{l}\text { Enhanced coverage, foliar } \\
\text { penetration, increased } \\
\text { availability of a.i. (insecticides) }\end{array}$ \\
\hline $\begin{array}{l}\text { Terpene derivatives } \\
\text { (polymer forming } \\
\text { compounds) }\end{array}$ & NuFilm & $\begin{array}{l}\text { Increased resistance of } \\
\text { foliar deposits to washoff. } \\
\text { Volatility reduction. }\end{array}$ \\
\hline $\begin{array}{l}\text { Polymers (polyacrylamide, } \\
\text { polyvinylalcohol) and } \\
\text { synthetic latex }\end{array}$ & $\begin{array}{l}\text { Atlas Companion, } \\
\text { Polycote Polymer }\end{array}$ & $\begin{array}{l}\text { Reduced droplet drift, } \\
\text { enhanced foliar retention }\end{array}$ \\
\hline Inorganic salts & Ammonium sulphate & $\begin{array}{l}\text { Increased penetration } \\
\text { (overcoming antagonism } \\
\text { by divalent cations) }\end{array}$ \\
\hline
\end{tabular}

In addition, there are many "bioactivator-type" materials which are included in formulations, which if tank-mixed would be termed adjuvants, but which are not commercially available in such a form. Adjuvant blends are also available.

There are several reasons for the proliferation of adjuvant usage. Clearly, as with the use of any agrochemical product, the material must provide a commercial advantage, i.e. they must pay for themselves! In general, tank-mix additives are used to reduce the rate of a commercial pesticide formulation whilst maintaining the activity. Often, such advantages have been found retrospectively. It may therefore be claimed that the original pesticide formulation was not optimised. The use of tank-mix additives may enhance the apparent spectrum of activity of a compound by enabling a herbicide to provide useful activity against difficult-to-control species. The use of tank-mix additives to maintain activity at reduced dose rates may also enable legal obligations to be met with regard to reduced pesticide inputs. In several countries (e.g. Denmark), authorities have set deadlines for reduced pesticide usage. Improved efficacy by adjuvant usage is one strategy to overcome apparent problems. In addition, harsh environmental conditions can necessitate the use of adjuvants in particularly challenging situations, for example the control of gorse in New Zealand forestry plantations (Balneaves et al. 1993). In some situations, the use of adjuvants has additionally provided benefit in overcoming apparent antagonism between different pesticides when they are tank-mixed. Such antagonism may arise from the tendency of some weakly ionic pesticides to form salts. The use of adjuvants can however increase foliar penetration of salts which have an innately lower penetration potential, an example being the tank-mixing of sethoxydim and sodiumbentazone (Wanamarta et al. 1993).

\section{MECHANISTIC STUDIES OF ADJUVANT MODE OF ACTION}

It has been established that the use of adjuvant materials can provide significant biological advantages. However, the reasons for enhanced biological activity have often been poorly understood; enhanced activity may be the result of several interacting factors. By concentrating upon specific unit processes which influence resultant biological activity, these mechanisms are gradually being understood. Adjuvants are used to target several sites of potential inefficiency in pesticide delivery, as outlined below.

\section{Spray atomisation}

Droplet size has a significant impact upon drift potential and efficiency of target retention. Polymeric adjuvants such as polyacrylamide reduce drift, by skewing the spray 
droplet spectrum to coarser droplet sizes, mainly due to effects on viscosity. In addition, emulsified oils can reduce the proportion of fine spray droplets.

\section{Foliar retention}

Model track sprayer studies have been conducted to investigate this phenomenon and have led to the design of models to explain the retention effect. In particular, dynamic surface tension of the spray solution plays a critical role for surfactant-containing sprays (e.g. Grayson et al. 1991). In addition to surface active materials, polyvinyl alcohol derivatives have been shown to enhance foliar retention. The superspreading effect of organosilicone materials can have a significant impact upon retention efficiency. Whilst the initial effect on retention may be beneficial, the subsequent superspreading may, depending on spray volume, lead to excessive runoff and a reduced net retention. The data in the following table illustrates the fall-off in retention as the rate of Silwet L-77 is increased.

\section{TABLE 2: Foliar retention $(\mu \mathrm{l} / \mathrm{g}$ fresh weight) of spray solutions containing various rates of Silwet $L-77$ after foliar application to apple trees using a mistblower to run-off, and to wheat using a flat-fan nozzle at 200 litre/ha application rate (Stock unpubl. data).}

\begin{tabular}{lrrrrr}
\hline & \multicolumn{5}{c}{ Rate of Silwet L-77 (\% w/v) } \\
Species & \multicolumn{1}{c}{0} & 0.025 & 0.05 & \multicolumn{1}{c}{0.1} & \multicolumn{1}{c}{0.2} \\
\hline Apple $^{1}$ & 308.7 & 359.5 & 180.5 & 148.2 & 188.7 \\
Wheat $^{2}$ (flagleaf) & 45.1 & 39.5 & 32.8 & 29.8 & 31.2 \\
\hline
\end{tabular}

LSD P $=0.05,61.8$ apples, 3.7 wheat.

${ }^{1}$ Mature Cox apple trees; ${ }^{2}$ WheatVariety: Tonic, GS 68.

This data was generated in the field under standard application conditions. Similar findings by Stevenset al. (1994) have suggested the need for alteration to commercial application practices to optimise the use of a.i. and minimise loss to run-off at higher spray volumes. The use of reduced spray volumes whilst maintaining efficacy will be particularly advantageous to operators.

\section{Foliar coverage}

It is often stated that good coverage is required for contact herbicides. This is inaccurate, as herbicides must penetrate into living tissues in order to exert their effect. Good coverage is not a guarantee of foliar penetration and this is readily demonstrable. In the case of insecticides, the size and placement of droplets can be critical, in addition to the physical properties of the droplet (notably viscosity) which governs the pickup of a.i. by motile insects.

Foliar coverage properties of conventional organic surfactants are relatively limited. For organosilicone materials, however, coverage can be complete and even extend into stomatal pores leading to penetration of substomatal cavities. Spreading effects have also been demonstrated with oil-type materials. This is particularly evident on plant species possessing microcrystalline epicuticular waxes, such as grass species.

\section{Foliar penetration}

Model system investigations have been concentrated on isolated plant cuticles. From such studies, it has been demonstrated that surfactant-type adjuvants can increase the diffusive mobility of pesticides across the cuticle, thereby increasing the penetration potential. In addition, surfactants can act as a solvent front when penetrating through the cuticle, the effect of the surfactant being reversible.

Studies on seed oil derivatives (alkyl oleates of varying chain length) have shown foliar penetration enhancement of both quizalofop-ethyl and phenmedipham (Serreet al. 1996). Such enhancement could not be correlated with the penetration rate of the alkyl oleates, nor their influence on the diffusion coefficient of the herbicide in leaf waxes. For quizalofop-ethyl, it was concluded that solubilisation by alkyl oleates on the leaf surface may play a significant role in foliar penetration. 
Penetration studies using intact organisms may be criticised for being subject to the confounding influence of many interacting variables. Intact plant studies with conventional nonionic organic surfactants have established that a relationship exists between surfactant structure and foliar penetration of pesticides. An optimum surfactant structure for penetration enhancement depends upon the physicochemical properties of the a.i., most notably lipophilicity as measured by $\log \mathrm{P}$ (log octanol-water partition coefficient).

Whilst many whole organism bioassays provide an immediate answer to the benefits of an adjuvant in a specific situation, the mechanistic understanding can be limited or non existent. Extrapolation is therefore not possible, necessitating further time-consuming and empirical biological screening of potential adjuvants. Conversely model systems, such as isolated cuticle investigations, can provide a greater degree of understanding of penetration phenomena. However, it must be recognised that direct measurement of cuticle penetration cannot necessarily be directly and proportionately correlated with resultant biological activity. The expression of biological activity is the summation of many processes, of which foliar penetration is only one. In addition, use of detached cuticles removes the influence of the physical state of the whole organism which can have a profound influence. For example, the mobility and continuing penetration of glyphosate into black nightshade (Solanum nigrum L) is influenced by the moisture status of the plant (de Ruiter and Meinen 1995).

\section{USING MECHANISTIC DATA FOR PRODUCT DESIGN: AN INDUSTRIAL PERSPECTIVE}

The value of data provided by mechanistic studies is debatable for numerous reasons. If mechanistic studies are to be of value for developing formulations with "built-in" adjuvants or tank-mix additives, it must be demonstrated that the predictive mechanistic element can be correlated with resultant biological efficacy.

It is vital that mechanistic considerations are related to real conditions of use. There are clear limitations regarding the amount of adjuvant which can be used per unit hectare on a tank mix basis, simply due to handling considerations. In addition, there are limitations to the amount of adjuvants which can be built into one-pack products, if we accept that adjuvants are formulation components. This is governed by considerations such at physical and chemical compatibility, in addition to acceptable pack-size (Stock 1996).

\section{FUTURE DIRECTIONS FOR ADJUVANT TECHNOLOGY Impact of biotechnology}

Within the industry at present, there is an increasing trend towards biotechnology and the use of genetically modified crops. Both herbicide tolerant and insect tolerant crops are already marketed and the development and marketing of disease tolerant crops is expected.

Herbicide tolerant crops, for example, crops resistant to the non-selective herbicide glufosinate, will still require chemical inputs. However, the portfolio of products used is likely to decline. In addition it is likely that the use of separate tank-mix additives will be vigorously opposed by R\&D agrochemical companies introducing the technology, with the emphasis on supplying optimised products for use on the partner crop. A new formulation of a herbicide may be required when herbicide tolerant genes are introduced into a novel crop as some built-in adjuvants may not be appropriate, as they may be phytotoxic to certain species.

Where insect resistant and disease tolerant crops are introduced, a reduction in chemical crop protection may be predicted and thus a reduction in adjuvant use. However, two principle problems with the transgenic solution to insect and disease tolerance are the narrow spectrum of control which is often seen and the possibility of development of resistance to the transgene. Additionally, resistance to one (or one group) of commercially important pathogens may simply increase the opportunities for infection by pathogens which had previously been out-competed. Stable, broad-spectrum disease resistance therefore seems a daunting task. Integrated pest management, incorporating chemical inputs is a means of overcoming these various problems. 
It is clear that biotechnology is unlikely to remove the use of chemical inputs entirely. The role for adjuvant-type technology will therefore be maintained as a means of minimising pesticide doses, within integrated crop management regimes. Indeed, it remains possible that biotechnology will provide new opportunities for adjuvants. It is proposed that engineered crops designed to produce modified materials should require a chemical "switch" to activate production of such materials when required. The application of a chemical switch will, like any conventional chemical, require an optimised delivery system and may open up opportunities for new adjuvant materials. Regulatory and environmental considerations

Of pivotal importance in determining the future of adjuvant materials is the future direction of regulations in countries in which adjuvants are sold. This is clearly linked with the issue of defining what an adjuvant material actually is, specifically, whether it is a separate tank-mix additive or part of the agrochemical formulation. Within Great Britain new formulations must pass through the full regulatory procedure, but for tankmix adjuvants, the system is frequently less stringent. Explicit studies with every adjuvant-pesticide formulation are not required, despite the fact that such combinations essentially result in a new formulation within the spray tank. Tank-mix additives are, however, likely to have a continuing role particularly under harsh conditions of use environment, and under extreme conditions of application. The poor image of adjuvant science will however be maintained if an industry-wide standard to the regulation of activity enhancing inert materials is not adopted.

\section{The changing nature of crop protection formulations}

A major factor which will influence the future of adjuvants as tank-mix additives is that of agrochemical formulations. Solvent based formulations, such as ECs, are less favoured due to transport, storage and operator safety (dermal penetration) issues. There may be an increased move towards dry formulations, such as granules and WP formulations (Frei and Schmid 1996). The latter can be provided in water soluble packaging to reduce problems of pack disposal. It must be recognised that changes in preferred formulation-type risks a move away from dose effective formulations. Many particulate, dry formulations tend to be less effective per unit dose, although this is not an absolute rule. As a means for offsetting this loss of activity, tank-mix adjuvants may enjoy favour.

As an alternative to the use of tank-mix adjuvants with innately less active formulation types, formulation answers within a one-pack context are still available. For example oilbased SC formulations of some active ingredients can be considerably more active than an aqueous SC whilst still being preferable to a solvent-based EC. Even dry formulations have the potential for inclusion of adjuvants. Liquid adjuvants, such as surfactants may be adsorbed onto inert fillers such as silica. In addition, some surfactants may be complexed with urea to produce dry urea-clathrates which may also be incorporated within formulations.

\section{The changing direction of adjuvant chemistry}

There are concerns regarding the biological properties of so-called inert adjuvants. Some adjuvants may induce phytotoxic symptoms, although this is highly species dependent, whilst many surfactant-type adjuvants can influence pathogen development.

The trend within the oil-type class of adjuvant is likely to continue to move towards vegetable oils and their derivatives due to the poor biodegredation of mineral oils (Cornishet al. 1993). Similarly, there is a trend in surfactant-type adjuvants to move from traditional materials towards products which have enhanced user/environmental safety and/or greater efficacy.

Traditional amine ethoxylate surfactants are now less favoured due to unfavourable fish toxicity profiles, whilst nonylphenol ethoxylates have recently been under public scrutiny for alleged oestrogenic side-effects. As apparent gaps in the portfolio of adjuvants appear, new candidates are required to maintain the potential for optimised pesticide delivery. In recent years, organosilicone surfactants have found a new and expanding niche. Whilst relatively expensive compared with conventional organic surfactants they can provide significant cost benefits due to effects on activity. Organosilicone surfactants are unique in providing the potential for stomatal infiltration. 
This can be a significant benefit for enhanced foliar penetration, and also has an associated benefit of increasing rainfastness due to the rapidity of penetration, with clear benefits in commercial practice.

Of newer "environmentally friendly" adjuvants there are alkylpolyglucoside materials which are derived from natural products. The use of such materials in the detergent industry has been established for several years. However, their use within an agrochemical context has become a subject of increasing interest.

\section{SUMMARY AND CONCLUSIONS}

In recent years, the use of adjuvants to maximise the dose efficacy of pesticides has been rejuvenated. Much of the growth in interest is motivated by commercial considerations, such as the escalating costs of discovering, developing and registering new active ingredients, in addition to the ongoing requirement to minimise pesticide loading in the environment.

The requirement for adjuvants is linked very closely with the fate of conventional crop protection chemistry. Provided that chemical control of weeds, insects and pathogens is required, a role for adjuvants is assured. However, the market positioning of adjuvants may undergo a significant change. It is increasingly likely, in the future, that adjuvants will, whenever possible, be built into formulations. If this is not possible, then the use of a tank-mix adjuvant will be very much part of the strategy of R\&D-based agrochemical companies, from the outset of product development.

\section{REFERENCES}

Balneaves, J.M., Gaskin, R.E. and Zabkiewicz, J.A., 1993. The effect of varying rates of glyphosate and an organosilicone surfactant on the control of gorse. Ann. App. Biol. 122: 531-536.

Cornish, A., Battersby, N.S. and Watkinson, R.J., 1993. Environmental fate of mineral, vegetable and transesterified vegetable oils. Pestic. Sci. 37: 173-178.

de Ruiter, H. and Meinen, E., 1995. Influence of surfactant and water stress on the efficacy, absorption and translocation of glyphosate.N.Z. FRI Bulletin No. 193:211216.

Frei, B. and Schmid, P., 1996. Development trends in pesticide formulation and packaging. Pp 33-42In: Pesticide Formulation and Adjuvant Technology. C.L.Foy and D.W. Pritchard (Eds). CRC Press.

Grayson, B.T., Webb, J.D., Pack, S.E and Edwards, D., 1991. Development and assessment of a mathematical model to predict foliar spray deposition under laboratory track spray conditions. Pest. Sci. 33: 281-304.

Serre, I., Cabanne, F. and Gauvrit, C., 1996. Behaviour of alkyl oleates on leaf surfaces in relation to their influence on herbicide penetration. Brighton Crop Prot. Conf. Pests and Diseases-1996: 807-812.

Stevens, P.J.G., Walker, J.T.S., Shaw, P.W. and Suckling, D.M., 1994. Organosilicone surfactants: tools for horticultural crop protection.Brighton Crop Prot. Conf. -Pests and Diseases-1994: 755-760.

Stock, D., 1996. Optimising the biological activity of crop protection formulations: design or chance ? Brighton Crop Prot. Conf. -Pests and Diseases-1996: 791-800.

Uttley, M.J., 1995. Adjuvant use in the USA and western Europe.N.Z. FRI Bulletin No. 193: 356-361.

Wanamarta, G., Kells, J.J. and Penner, D., 1993. Overcoming antagonistic effects of Nabentazon on sethoxydim absorption. Weed Tech. 7: 322-325. 